El poder de los mapas, los mapas del poder: la construcción del saber geográfico de Patagonia-Aysén Andrés Núñez G. - Antonia Zambra-A. - Enrique Aliste A.

Pp. 149-162

\title{
EL PODER DE LOS MAPAS, LOS MAPAS DE PODER: LA CONSTRUCCIÓN DEL SABER GEOGRÁFICO DE PATAGONIA-AYSÉN ${ }^{1}$
}

\author{
The power of maps, the maps of power: The construction of geographic \\ knowledge about Patagonia-Aysén
}

\author{
Andrés Núnez González* \\ Antonia Zambra-Alvarez** \\ Enrique Aliste Almuna**
}

\begin{abstract}
RESUMEN
El artículo se interroga sobre cómo determinados mapas y prácticas cartográficas, asociadas a discursos hegemónicos, han participado de los procesos de formación territorial e imaginación geográfica de Patagonia-Aysén. Este ha sido durante el siglo XX y lo que va del actual siglo XXI, un territorio concebido desde una lógica centro-periferia. Las prácticas discursivas que subyacen a esta lógica han establecido formas particulares de representación de esta región, logrando permear el saber geográfico de la nación. El análisis de determinados mapas desde una perspectiva hermenéutica, se constituye aquí
\end{abstract}

\footnotetext{
${ }^{1}$ El presente texto es posible gracias al apoyo de Conicyt a través de los proyectos Fondecyt Regular $\mathrm{N}^{\circ} 1141169$, titulado:"Fronteras tardías, fronteras actuales: el territorio de Aysén en la construcción del imaginario geográfico de la nación. Chile, siglos XX-XXI" y No 1170643, titulado: "El discurso de la Naturaleza en Patagonia-Aysén: nuevos imaginarios geográficos en la producción del espacio de la nación (Chile, 1990-2016).

* Pontificia Universidad Católica de Chile, Instituto de Geografía. Santiago, Chile. Correo electrónico: aanunezg@uc.cl

** Universidad Católica Silva Henríquez, Facultad de Educación, Pedagogía en Historia y Geografía. Santiago, Chile. Correo electrónico: azambra@ucsh.cl

*** Universidad de Chile, Departamento de Geografía. Santiago, Chile. Correo electrónico: ealiste@uchilefau.cl
}

Artículo recibido el 14 de septiembre de 2016. Aceptado el 25 de abril de 2017 
un elemento relevante para explicar y comprender desde dónde surge la construcción de esta Patagonia imaginada. Nuestro objetivo fue la deconstrucción y reconstrucción del discurso detrás de ciertas representaciones cartográficas elaboradas en diferentes contextos geográfico-históricos.

Palabras clave: mapas, imaginario geográfico, hermenéutica filosófica, conocimiento, poder.

\begin{abstract}
This article discusses how certain maps and cartographic representations, associated to hegemonic discourses, have participated in the processes of territorial formation and imagined geographies of Patagonia-Aysén. During the 20th century and so far during the 21 st century too, Patagonia-Aysén has been a space conceived from a centre-periphery logic. The discursive practices associated to this logic have established particular forms of representation of the region, which have passed to the geographical knowledge of the nation. From an hermeneutical perspective, the analysis of maps becomes an important element to explain and comprehend where does the construction of this imagined Patagonia come from. Our aim was the deconstruction and reconstruction of the discourse behind certain cartographical representations which where elaborated in different historical-geographical contexts.
\end{abstract}

Keywords: Maps, geographical imaginary, philosophical hermeneutic, knowledge, power.

\title{
INTRODUCCIÓN
}

A partir de la década de los 80 la imagen cartográfica comienza a ser revisitada desde una perspectiva crítica, cuestionando el rol descriptivo de carácter neutral desde donde había logrado posicionarse a lo largo de la historia. Este cuestionamiento, favorecido por el giro lingüístico/cultural que experimentarán las ciencias sociales de la segunda mitad del siglo XX, seńala que el espacio representado a través del mapa, lejos de poseer un carácter objetivo y científico-técnico, constituye una imagen cargada de intencionalidad que actúa como metáfora visual de aquellos lugares que pretende representar (Lois, 2014; Harley, 2005). Por otro lado, el manejo y proliferación de determinados mapas deja entrever que existen cartografías que actúan como mecanismos de poder y control visual mediante la capacidad de materializar, objetivar y manipular estas imágenes. Desde una visión de poder, el peso discursivo de estos mapas influye en el proceso desde el cual las personas se apropian de dichas imágenes y las articulan con otras que ellas mismas han elaborado, construyendo así una compleja trama de sentido espacial desde donde surge el imaginario geográfico (Hiernaux y Lindón, 2012). 
Pero, ¿cómo han participado los mapas en la construcción de estas representaciones? y ¿cómo influyen, a su vez, estas espacialidades imaginadas en la producción de cartografías? Bajo esta reflexión buscamos dar cuenta de prácticas cartográficas asociadas a discursos hegemónicos que han constituido parte importante de los procesos de formación territorial de Patagonia-Aysén. Este espacio proyectado, concebido bajo una lógica centro-periferia, ha establecido formas de representación basadas en su entendimiento como frontera o límite que han permeado la geografía social y el imaginario de esta región (Aliste, 2011; Núńez et al., 2014). Para interpretar estas representaciones transmitidas desde la tradición, resulta necesario movilizar aquellas reflexiones históricas que nos permitan esclarecer dónde y cómo se formularon ciertas ideas, cuál es el verdadero motivo de su formulación y, por tanto, su sentido. En este marco, nos posicionamos desde la hermenéutica filosófica (Gadamer, 1999; Ricoeur, 2002) a fin de explicar y comprender cómo determinados contextos geográfico-históricos de la nación, es decir, el horizonte temporal desde donde se expresa el saber geográfico, incidieron en el desarrollo de procesos de producción cartográfica que buscaban responder a necesidades territoriales particulares en Patagonia-Aysén, desde los objetivos estratégicos del Estado chileno.

De esta manera buscamos analizar, en primera instancia, cartografías que nos permitiesen comprender esta dinámica centro-periferia, cuyas representaciones han influido en el imaginario geográfico de la nación hasta hoy. En segundo lugar, mapas que actuaron como dispositivos de poder colaborando al desarrollo de diferentes mecanismos de control y apropiación territorial en Patagonia-Aysén. Para ello, seleccionamos dos cartografías de diferentes contextos geográfico-históricos entre el siglo XIX y XX. Ambas, desde nuestro punto de vista, son representativas de la utilidad con que la cartografía colaboraba a definir el significado geográfico de esos australes territorios.

\section{¿MAPAS PARLANTES? LA CARTOGRAFÍA COMO TEXTO, FORMACIÓN DISCURSIVA Y PRÁCTICA ESPACIAL}

Desde la producción y confección de los primeros mapas, hemos conocido y aceptado su utilidad y adecuación para comunicar la presencia de los elementos de nuestro entorno geográfico (Silvestri, 2002). Este papel cientificista de la cartografía, que con el paso del tiempo ha ido perfeccionando sus técnicas y profundizando su nivel de precisión, constituye, sin embargo, solo parte de la funcionalidad del mapa como instancia comunicativa. En este sentido, Harley (2005) precisa que los mapas son imágenes 'inherentemente retóricas' que proyectan un 'mundo ficticio' donde podría vivirse. De esta manera, el mapa, como texto, posee una función 
referencial que, a través del juego entre la imagen y el lenguaje, se abre ante el sujeto/lector para ser interpretado y reinterpretado en distintos contextos históricogeográficos. Ahora bien, este 'mundo texto' como unidad del lenguaje se constituye en formación discursiva en tanto posee la intencionalidad de poner de manifiesto a través de la cartografía una forma particular de 'estar en el mundo'. El discurso como una instancia del lenguaje es, por tanto, la mediación entre el mapa (el signo) y el imaginario geográfico (la cosa representada), el cual se disuelve en huellas, espacios vacíos, líneas, para ser reconocido como aquel proceso ideal/abstracto que ha sido esquematizado (Silvestri, 2002). Aquella construcción discursiva es así constantemente reinterpretada. En otras palabras, es el resultado de una interacción de la apropiación del sentido espacial: sujeto y objeto se funden en un horizonte efectual donde el "comprender" es, finalmente, diálogo (fusión de horizontes) entre la experiencia comprensiva (sujeto social) y la convivencia del horizonte histórico de la comprensión (objeto) (Gadamer, 1999). Como ha expresado Deleuze: "Una época no pre-existe a los enunciados que la expresan, tampoco a las visibilidades que la ocupan" (1987, p. 77).

Figura 1. Ejercicio de deconstrucción y recuperación del sentido cartográfico

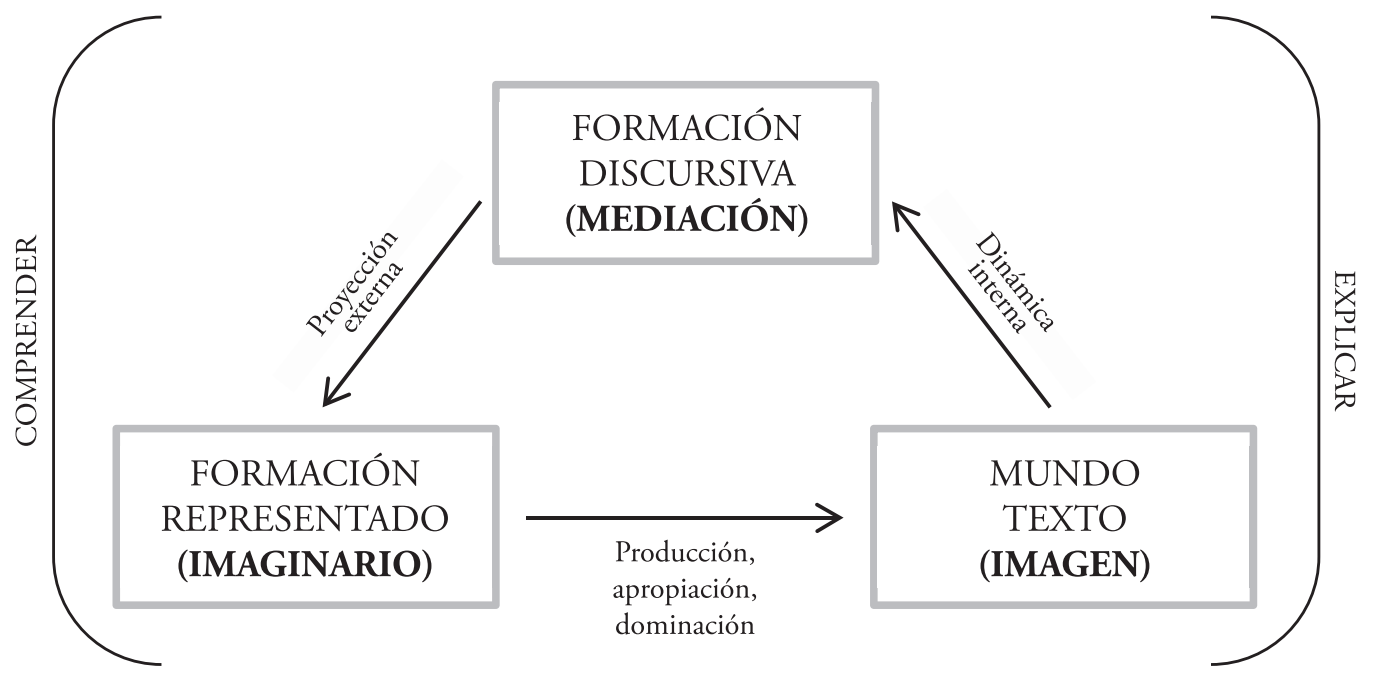

Fuente: Elaboración propia.

El espacio representado se constituye o compone, sin embargo, más allá de la imagen misma. Nos referimos con ello a que la construcción del imaginario geográfico está asociada también a una práctica espacial en la medida que el 'mundo texto', aquel que es formulado y proyectado, se encuentra necesariamente con el 'mundo real' para rehacerlo una y otra vez (Ricoeur, 2002). Desde esta perspectiva, la cartografía se concibe no como condición de mapa-objeto, sino como dispositivo visual que surge en un marco socio-cultural determinado, que, en el fondo, también 
va definiendo el sentido del saber geográfico. Es práctica espacial en la medida que ideas y valores en épocas específicas orientan la lectura que se hace de ciertas imágenes concebidas como representativas de la relación entre la sociedad y el entorno (Zusman, 2013). Por consiguiente, el carácter performativo o cambiante de los mapas, permite que 'aquel mundo proyectado' a través de la cartografía esté constantemente siendo relevado por otros discursos en diferentes contextos históricos (Lois, 2014). El espacio representado, en tanto testimonio a través del mapa, logra trascender de esta manera su condición de objeto constituyéndose así en un proceso, es decir, en historicidad (Núńez, 2013b). El estudio de un corpus de mapas en este sentido, implica trabajar sobre aquellas capas de historicidad que nos permitan analizar estos procesos así como los contextos de producción, las connotaciones ideológicas y la potencia discursiva que dio lugar al conjunto de obras, en una cultura visual determinada (Lois, 2014).

Como señala Gadamer (1999), no hay ningún enunciado que sea únicamente el contenido que propone. La tarea de hacer explícita esta referencia del 'mundo texto' ha sido una tarea emprendida tanto desde lógicas posestructuralistas como hermenéuticas ${ }^{2}$. Todo enunciado posee una motivación y es tarea de la disciplina hermenéutica interpelar, mediante la interpretación, dicho enunciado. En este contexto, el ejercicio de interpretar se asimila a extraer de los elementos de la imagen aquellos 'mundos proyectados' por los mapas. Nos referimos entonces a un ejercicio de recuperación del sentido cartográfico, a través del acto de explicar y comprender (Figura 1). 'Explicar' en la medida que buscamos poner de relieve la estructura oculta de los procesos detrás de la obra. 'Comprender' en la búsqueda por reproducir el proceso temporal que dio lugar a la obra (Ricouer, 2002).

\section{CARTOGRAFÍA COMO ESPEJO SOCIAL: LA PRODUCCIÓN DEL IMAGINARIO GEOGRÁFICO DE PATAGONIA-AYSÉN}

La capacidad de materializar, objetivar y manipular imágenes que las personas tienen sobre su espacio (espacio abstracto), se articula con la generación de otras imágenes que ellas mismas han elaborado desde su experiencia individual (espacio vivido), construyendo una trama de imágenes, valores y significados que reconoceremos como imaginario geográfico (Hiernaux y Lindón, 2012). En torno a la imagen referente o 'mapa logotipo', al que hace referencia Anderson (1991),

\footnotetext{
${ }^{2}$ Nos parece relevante resaltar el rol del quehacer hermenéutico en la constitución del saber geográfico. Ello impone relativizar la preponderancia excesiva dada a la fecha a las llamadas ciencias "duras" o "científicas" en el trabajo de comprensión geográfica. Al respecto, Aliste et al., 2015; Núñez et al., 2016.
} 
se construyen vínculos sociales, se genera un sentido de identidad, se configuran aspiraciones y se constituyen formas de apropiación y acción sobre el espacio geográfico. En otra palabras, refiere a la capacidad de la obra para proyectarse fuera de sí misma y engendrar un sentido común geográfico que se vuelve necesariamente el sentido del texto o del mundo proyectado (Ricoeur, 2002). Corpus de imágenes cuya información funcional y estructural dirigen el límite de lo conocido y neutralizan aquellos significados que no responden a los intereses de organismo central (Lois, 2012). El espacio concebido reduce entonces 'lo vivido' a los límites de 'lo visible', lo legible (Lefebvre, 2013). Por lo mismo, es el resultado de una combinación entre una visión de poder, a través de la institucionalización, producción y difusión de un espacio abstracto, y de aquellas prácticas socio espaciales locales (Núnez et al., 2014).

En Patagonia-Aysén la proyección de esta imagen referente y la configuración de un imaginario geográfico común, ha ido decantando a lo largo del tiempo bajo una lógica centro-periferia, donde la Patagonia, no necesariamente administrativa, constituye un área aislada, marginal. Es decir, una tierra "otra" y extraña que requiere integración al corpus discursivo de la nación. La vigencia y actualidad de este saber común geográfico de carácter centralizado, en detrimento de una multi-inter territorialidad a micro escala, de historicidades específicas y en una región periférica invisibilizada, ha sido plasmada también en los procesos de representación cartográfica (Núnez, 2013). Desde el punto de vista de la Geografía esto ha significado la imposición del 'espacio abstracto' sobre el 'espacio vivido', garantizando la efectividad de procesos de apropiación territorial a través de diversos mecanismos de control desde la centralidad. Desde la Geografía Histórica ello ha demostrado la importancia de este imaginario común para denominar y dominar áreas específicas del territorio, menoscabando otras formas de organización política.

\section{El 'vaciamiento cartográfico' y la 'naturaleza útil' en la colonización de Patagonia-Aysén}

A mediados del siglo XIX, la economía del mundo y la división geográfica del trabajo también se producirá con ayuda de documentos geográficos como los mapas (Harley, 2005). El proyecto del Estado chileno en formación consideraría la demanda de materia prima proveniente de los mercados extranjeros para el desarrollo de una naciente economía, que requirió de ciertos territorios para darles aprovechamientos de exploración y explotación (Hevilla, 1998). De esta manera, un nuevo imaginario civilizatorio buscaría proyectarse en la cartografía, atribuyendo especial importancia a la necesidad de conocer la zona interior de esta región en vistas al aprovechamiento de sus recursos naturales y espacios para la futura colonización.

La Carta de Chile (Mapa 1) encargada al ingeniero-geógrafo Alejandro Bertrand, y contenida en la obra de Pedro Lucio Cuadra (1877) es muy ilustrativa 
al respecto. En efecto, el mapa le fue encargado para definir y difundir la división político-administrativo a nivel nacional. Por lo mismo, junto con explorar, Bertrand se posicionó en información previamente desarrollada, como las obras de Fitz-Roy, Pissis, ya contenidas parcialmente en la primera obra de Cuadra "Apuntes sobre geografía física i política de Chile" (1866) ${ }^{3}$. La Carta de Chile de 1877 contenía 4 láminas, siendo la cuarta la que involucraba a la zona austral. Ella es muy ilustrativa de los lenguajes sociales y políticos con que estaban imbuidos los mapas. El contexto de la obra es el de la proyección de una nación en consolidación. Así, el mapa se transformó en una poderosa herramienta en aquella misión.

Mapa 1. Mapa de la zona sur-austral, de Alejandro Bertrand. En la obra "La Carta de Chile" de Pedro Lucio Cuadra de 1877

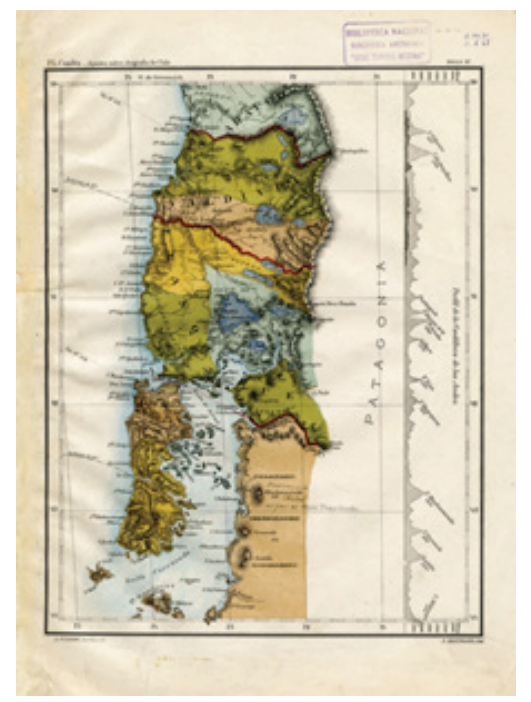

Fuente: Biblioteca Nacional de Chile.

En efecto, el mapa en cuestión, por una parte, es muy claro respecto del "vaciamiento" necesario en zonas menos exploradas. Con ello, no solo quita peso político a un área no definida aun sino que invisibiliza la existencia de grupos aborígenes e identidades locales. Ello no porque hayan desaparecido, sino porque la política de homogenización nacional implicaba el ocultamiento de 'lo indígena' (Núnez, et al., 2016). Por otra parte, el Mapa Político de Chile confeccionado por el ingeniero Bertrand colaboró a construir un nuevo imaginario de colonización proyectado en estas 'tierras de entremedio', (Bandieri, 2011) para referirse a esa porción de tierra entre las provincias de Llanquihue y Magallanes (Núnez et

\footnotetext{
${ }^{3}$ Bertrand fue posteriormente jefe del personal técnico de la Comisión Chilena de Límites.
} 
al., 2014). Es decir, queda "desértica" hasta que esté realmente incorporada a la nación.

La obra de Bertrand excluirá todo objeto fuera de la realidad del cartógrafo, deshumanizando el paisaje Patagónico y re-identificándolo como un espacio en blanco socialmente vacío. Como seńala Harley (2005), este espacio en blanco se establece como actuación activa -es decir, no pasiva, neutra- en términos de impacto social y político, así como de sus efectos en el imaginario geográfico de la nación en construcción. Los nombres indígenas de los lugares serán suprimidos en favor de una toponimia o simbología estandarizada desde la nueva estatalidad, la que se repetirá con escasas variaciones. A partir de estas omisiones, comenzarán a aparecer nuevas características en el terreno que describen o enfatizan el nuevo propósito cartográfico. Del mapa se desprenderá aquel imaginario de soledad en la naturaleza (volcanes, ríos), que hace alusión al despoblamiento del indígena ${ }^{4}$ a su vez que representa aquellas aspiraciones de colonización (“Territorio de Colonización Magallanes”) e institucionalización de este territorio ("Provincia de Chiloé hasta Cabo Tres Montes")". La atribución de signos sobre el terreno será un fenómeno tardío del siglo XIX y los referentes semánticos durante este período solo existirán de manera potencial como expectativa o de forma imaginaria, haciendo alusión a la incorporación de PatagoniaAysén como parte de la identidad y unidad nacional.

\section{CONOCIMIENTO Y PODER: EL MAPA COMO DISPOSITIVO DE CONTROL TERRITORIAL}

Estudiar las representaciones del espacio geográfico desde su historicidad y formación discursiva, como productoras de significados e imaginarios geográficos, nos lleva necesariamente a abordar aquellos procesos de configuración cartográfica que se articulan desde una visión de poder (Núñez et al., 2014). Si tenemos en cuenta que el saber geográfico es historicidad y contexto temporal, debemos admitir que quien cartografía intenta plasmar una perspectiva determinada del espacio geográfico. Así, reconocemos la existencia de mapas que se configuran como mecanismos de control del territorio y buscan justamente producir y legitimar cierto tipo de encuadres, eliminando con ello otras significaciones territoriales en busca de establecer una

\footnotetext{
${ }^{4}$ Como señalaba Enrique Simpson (1870): "La raza indígena ha desaparecido completamente", o José Pomar (1923): "La Patagonia ya no es esa 'África Tenebrosa' que nos imaginábamos al estudiar geografía cuando niños; hoy ha dejado de ser el país de indios tolderos que se alimentaban de guanacos, avestruces y manzanas y se vestían con pieles".

${ }_{5}^{5}$ Que ya en 1927, bajo el gobierno de Carlos Ibáńez del Campo, pasó a transformarse en la nueva Provincia de Aysén.
} 
única mirada del mundo (Ther, 2012). Nos referimos con ello a 'mapas de poder' (y, por lo mismo, el poder de los mapas), en tanto configuran un relato que monopoliza el lenguaje y que es a su vez un lenguaje aceptado socialmente (Núñez, 2013b).

\section{El discurso cientifico en los mapas: la precisión como una herramienta de poder en el proceso de conformación de la frontera del Estado moderno}

A fines del siglo XIX, la noción del potencial geográfico-productivo de Patagonia-Aysén fue asumida por hombres de ciencia que comenzaron a elaborar cartografías bastante más precisas que las cartas conocidas hasta la década de 1880 , incluida la de Bertrand (Martinic, 2005). Hasta esa fecha, los trabajos cartográficos tenían como principal objetivo resolver problemas y necesidades prácticas en el territorio (Rosenblitt y Sanhueza, 2010). El relevamiento que el imaginario de Patagonia-Aysén experimentará en ese momento, irá acompañado por ciertos procesos históricos importantes de mencionar. En primer lugar, una creciente mirada estatal sobre la frontera que buscaba consolidar la nación en formación, pero cuyo escaso conocimiento sobre el territorio le impedía reunir la información espacial y estadística necesaria para la organización de la república (Rosenblitt y Sanhueza, 2010). A este antecedente se sumaban diversos intentos geopolíticos de parte de otros países (Perú, Bolivia, España, Argentina) por ejercer soberanía en territorio nacional ${ }^{6} \mathrm{y}$ que, en el transcurso del siglo XIX, contribuirán a reforzar la urgencia del Estado chileno por argumentar la delimitación de sus fronteras.

En la región patagónica esta necesidad se reflejará, sobre todo, en relación a la disputa territorial con la República Argentina que culminará, en 1902, mediante un arbitraje ante la Corona británica para definir los límites entre ambos países. Para cumplir este propósito, tanto Chile como Argentina harán ejercer la creciente influencia de un modelo científico positivista ${ }^{7}$ que buscará la objetividad del conocimiento, desprovisto de aquel tono confesional e intimista asociado a la crónica de viaje ${ }^{8}$. Adquirida a partir de la observación directa de los fenómenos, la ciencia positiva se constituirá

\footnotetext{
${ }^{6}$ Guerra contra la Confederación Perú-Boliviana (1837-1839), Guerra contra España (1865-1866), Guerra del Pacífico (1879-1883), Conflicto limítrofe con la República Argentina (1850-1901).

${ }^{7}$ A mediados del siglo XIX Augusto Comte (1798-1857), considerado el creador del positivismo y la sociología argumentaría la necesidad de 'hacer ciencia positiva' como punto de apoyo fundamental para un futuro de orden y progreso. El concepto de ciencia es llevado a un extremo conocido filosóficamente como 'materialismo' (Zambra, 2010).

${ }^{8}$ Del diario de exploraciones de Hans Steffen (1892-1902): "Nuestro diario no presenta esas animadas relaciones o descripciones entretenidas de accidentes que a veces ocurren al viajero y que son buscadas en trabajos de esta naturaleza por lectores curiosos; hemos preferido dar, siguiendo nuestro itinerario, una sencilla descripción topográfica de las regiones recorridas; insertando datos referentes a la geografía física y geología de ellas".
} 
como un mecanismo válido para la identificación del 'conocimiento auténtico' y, por consiguiente, para la delimitación de las fronteras ${ }^{9}$ (Zambra, 2010). Así, la definición fronteriza dejará de ser durante este período solo un asunto jurídico, para ser entendida como una construcción de saberes geográficos donde la ciencia se transforma en el nuevo 'instrumento de expansión imperial' (Rosenblitt y Sanhueza, 2010).

Sin embargo, es solo a fines del siglo XIX que Chile encontrará la base económica y política necesaria para materializar un proyecto de tal envergadura como la elaboración de una carta nacional de precisión cartográfica. A modo de cumplir con este objetivo, la contratación de profesionales extranjeros por parte del gobierno para la realización de viajes con fines científicos será una constante a lo largo del siglo XIX (Rosenblitt y Sanhueza, 2010). Específicamente respecto al conflicto limítrofe entre Chile y Argentina en Patagonia, los trabajos de la Comisión Chilena de Límites, publicados entre 1903 y 1911, no solo perfeccionarán la obra de José Amado Pissis' de $1888^{10}$, sino que se constituirán como el estandarte oficial del Estado chileno para legitimar su soberanía en este territorio.

El mapa 'La cordillera de los Andes entre las latitudes $46^{\circ}$ y $50^{\circ}$ sur' (escala 1.000.000), (Mapa 2) levantado por un equipo de ingenieros geógrafos de la Comisión bajo la dirección de Luis Risopatrón, da cuenta de la tendencia de la época por valorar lo tangible y lo observable (hidrografía, topografía, meteorología) a modo de validar los propósitos geopolíticos del Estado chileno (Rosenblitt y Sanhueza, 2010; Zambra, 2010).

\section{Mapa 2. 'La Cordillera de los Andes entre las latitudes $46^{\circ}$ y 50 S' de 1905}

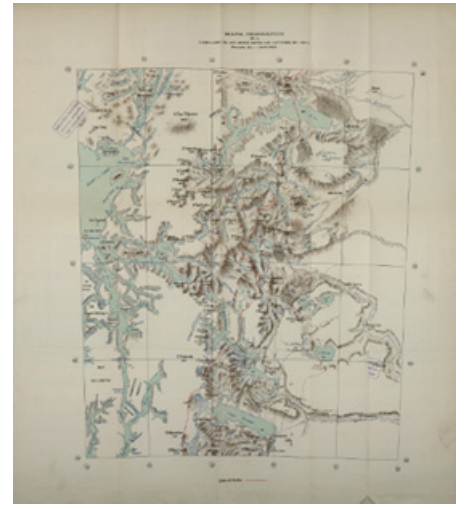

Fuente: Biblioteca Nacional de Chile.

\footnotetext{
9 "La disciplina científica es la única que podrá delimitar el concepto geográfico de cualquier región o zona terrestre que esté en las condiciones de la Patagonia” (Sociedad Geográfica Alemana, 1917). ${ }^{10}$ Contratado en 1848 por el Estado chileno, la obra del geógrafo y geólogo francés José Amado Pissis, se constituye como una de las primeras empresas oficiales de elaboración cartográfica estatal cuyo resultado son las primeras cartas del espacio geográfico chileno con base científica. El 'Mapa de la República de Chile desde el río Loa hasta el Cabo de Hornos' (1888), escala 1:1.000.000, criticado por haberse observado diversos errores de medición sobre todo entre los $38^{\circ}$ y los $42^{\circ}$ latitud sur.
} 
Esta cartografía de 1905 sintetiza, tanto en su contenido como a partir de la 'línea de límites' (en color rojo), la información científica-geográfica levantada durante cincos campañas de expedición entre 1897 y 1902 por miembros de la Comisión Chilena de Límites en Patagonia Occidental. El mapa refleja, a su vez, la resolución del tribunal arbitral británico luego de las discrepancias existentes entre ambos países respecto a los criterios de demarcación de la frontera. Mientras que Chile abogaba por reconocer la 'divisoria de aguas continentales' (divortium aquarum) como criterio principal, Argentina defendía la 'alta línea de cumbres' (Argentina) como el más relevante mecanismo de discernimiento respecto a los límites de frontera. La carta, en este caso, constituye una conjugación entre ambos criterios $^{11}$, que busca resaltar sobre todo las características hidrológicas del lado occidental Patagónico.

Si bien la divisoria de aguas pretendida por Chile se encontraba desplazada unos kilómetros más en dirección hacia el este, el argumento de la nación (basado en su evidencia científica) logra ser representando en esta cartografía del sector sur de Patagonia-Aysén. Así lo ilustran en las observaciones de Luis Risopatrón respecto a la labor final de la Comisión para el establecimiento de hitos en terreno:

Desde la boca del Jeinemeni o Necromani, hasta la divisoria de los ríos Chacabuco i Gio [ver $72^{\circ}$ Long $\mathrm{O} ; 47^{\circ}$ Lat S], la línea no admite ambigüedades. En el Cordón Nevado hubiera sido mui dificultoso la colocación de hitos, pero corriendo la línea por la divisoria de las aguas, se puede confiar en que el asunto no se prestará jamás a dudas (Comisión Chilena de Límites, 1905, p. 208).

Lejos de ser incompatible con el poder simbólico, la línea fronteriza en este período, se constituye como parte del nuevo estandarte de autoridad y apropiación del territorio. En otras palabras, el contorno del mapa representará la nueva frontera de aquel imaginario geográfico posible (Baeza, 2009; Livon-Grosman, 2003). Imaginario geográfico donde confluye, esta vez, el saber científico con el interés político, presentando valores propios de un Estado territorial en formación disfrazado del desinterés de la ciencia y que significará, para ambos países, hacer efectivo el derecho a legislar y a ejercer un control sobre este espacio para los propósitos de colonización del siglo XX (Harley 2005; Sanhueza, 2014; Silvestri, 2002).

\footnotetext{
11 'Levantamiento de poligonales jeodésicas siguiendo el curso de los ríos i desde cuyos vértices se dirijan visuales a las cumbres de los cordones de los cerros' (Comisión Chilena de Límites, 1905, p. 13).
} 


\section{CONCLUSIONES}

La naturalización de la cartografía como un elemento de representación meramente descriptivo u objetivo, sin tomar en cuenta los marcos discursivos desde donde surge la imagen geográfica y su vínculo estrecho con el poder, nos llevó a indagar respecto de la particularidad de los mapas sobre Patagonia-Aysén como dispositivos de abstracción y normalización del saber geográfico de la nación. Desde una perspectiva hermenéutica, este análisis significó un proceso de desconstrucción de la obra. En otras palabras, implicó un intento por mantener el nexo que el 'mundo proyectado' en estas cartografías poseía con sus contextos temporales, así como también visualizar a través de ellos aquella 'Patagonia imaginada' con que la sociedad se reconoce geográficamente hasta el día de hoy (Gadamer, 1999). Los mapas analizados nos instaron a identificar determinadas miradas con que la sociedad política narraba a los territorios australes de Aysén: primero como espacio vacío y luego con toda la precisión exigida para materializar los límites demandados por la nación. En la medida que nos planteamos como principal objetivo la deconstrucción del discurso detrás de ciertas representaciones cartográficas, la cartografía se constituye en un elemento relevante para analizar desde dónde surge la construcción de esta Patagonia-Aysén. Los discursos de modernidad y de colonialidad interna insertas en tales representaciones parecieran converger siempre en torno al papel de la propiedad y la economía: ambas constituyeron las primeras proyecciones de dicho territorio a inicios del siglo XX.

De este modo, la geografía de Patagonia-Aysén es, en el fondo, experiencia, tradición e historicidad (Aliste et al., 2015). Por lo mismo, una renovada manera de enfocar el "problema geográfico", supondrá considerar la experiencia (temporalidad) o historicidad del espacio como soporte esencial de la interpretación que el sujeto social se hace de él. En otras palabras, como ha expuesto Gadamer (1999) la interrogación del espacio implicará tener en consideración tanto la perspectiva comprensiva del sujeto como, a su vez, "la situación hermenéutica a la que pertenece" aquella comprensión.

\section{REFERENCIAS}

Aliste, Enrique. "Territorio y huellas territoriales: una memoria del espacio vivido en el Gran Concepción, Chile”, Desenvolvimento e Meio Ambiente, 23 (2011): 25-38.

Aliste, Enrique y Núñez, Andrés. "Las fronteras del discurso geográfico: el tiempo y el espacio en la investigación social”, Chungará, 47/ 42 (2015): 287-301. 
Anderson, Benedict. Comunidades imaginadas. México: Fondo de Cultura Económica, 1991.

Baeza, Brígida. Fronteras e identidades en Patagonia Central. Rosario: Protohistoria Ediciones, 2009.

Bandieri, Susana. Historia de la Patagonia. Buenos Aires: Sudamericana, 2011.

Deleuze, Gilles. Foucault. Barcelona: Editorial Paidós, 1987.

Gadamer, Hans-Georg. Verdad y Método I y II. España: Sígueme Ediciones, 1999.

Harley, John Brian. La nueva naturaleza de los mapas. Ensayos sobre la historia de la cartografía. México: FCE, 2005.

Hevilla, María Cristina. "El estudio de la frontera en América. Una aproximación bibliográfica”, Revista Bibliográfica de Geografía y Ciencias Sociales, 125 (1998): 1-13.

Hiernaux, Daniel y Lindón, Alicia. "Renovadas intersecciones: la espacialidad y los imaginarios”. En Daniel Hiernaux y Alicia Lindón (Eds.), Geografías de lo imaginario. Espańa: Anthropos Editorial, (2012): 9-28.

Lefebvre, Henri. La producción del espacio. España: Capitán Swing Libros, 2013.

Livon-Grosman, Ernesto. Geografias imaginarias. El relato de viaje y la construcción del espacio patagónico. Rosario: Beatriz Viterbo Editora, 2003.

Lois, Carla. Mapas para la nación. Episodios en la historia de la cartografía argentina. Argentina: Editorial Biblos, 2014.

Martinic, Mateo. De la Trapananda al Aysén: una mirada reflexiva sobre el acontecer de la Región de Aysén desde la prehistoria hasta nuestros dias. Santiago de Chile: Pehuén, 2005.

Navarro Floria, Pedro. Paisajes del progreso: la re significación de la Patagonia norte 1880 - 1916. Argentina: Universidad Nacional del Comahue, 2007.

Núñez, Andrés. "Definiendo una geografía para la nación: la re significación territorial de Chile, siglos XVIII - XIX”. En Quim Bonastra y Gerard Jori. Imaginar, organizar controlar el territorio. Una visión geográfica de la construcción del Estado. España: Icaria Editorial (2013): 167-195. 
Núñez, Andrés. "Geografía, historicidad y hermenéutica”, Revista de Geografía Norte Grande, 54 (2013b): 257-268.

Núñez, Andrés; Aliste, Enrique y Bello, Alvaro. "Patagonia-Aysén en la construcción del imaginario geográfico de la nación”, Itzapalapa, Revista de Ciencias Sociales y Humanidades, 76 (2014): 165-188.

Núñez, Andrés; Molina, Raúl; Aliste, Enrique y Bello, Alvaro (2016). “Silencios geográficos en Patagonia-Aysén: territorio, nomadismo y perspectivas para re-pensar los márgenes de la nación en el siglo XIX”, Magallania, 44 /2, (2016): 107-130.

Ricoeur, Paul. Del texto a la acción. Ensayos de hermenéutica II. México: Fondo de Cultura Económica, 2002.

Risopatrón, Luis. La cordillera de los Andes entre las latitudes 46 i 50 S. Santiago de Chile: Cervantes, 1905.

Rosenblitt, Jaime y Sanhueza, Carolina. Cartografía Histórica de Chile. Santiago de Chile: Biblioteca Fundamentos de la Construcción de Chile, 2010.

Silvestri, Graciela. "La pampa y el río. Una hipótesis de registros y periodizaciones en el paisaje rioplatense", Materia, 2 (2002): 75-96.

Ther, Francisco. "Antropología del territorio", Polis, Revista de la Universidad Bolivariana, 11/32 (2012): 493 - 510.

Zambra, Marcelo. “Discusiones epistemológicas”. Curso de Formación General 'Historia de la Ciencia: inflexiones e impactos en la sociedad'. Universidad Diego Portales. marzo, 2010. Texto no publicado, inédito.

Zusman, Perla. La geografía histórica, la imaginación y los imaginarios geográficos. En Revista de Geografia Norte Grande, 54 (2013): 51 - 66. 